\title{
On the Relationship between Azimuth Dependency of Earthquake Ground Motion and Deep Basin Structure beneath the Osaka Plain
}

\author{
Takao Kagawa, ${ }^{*}$ Sumio Sawada, and Yoshinori Iwasaki \\ Geo-Research Institute, Osaka Soil Test Laboratory, \\ Nishi-ku, Osaka 550, Japan
}

\begin{abstract}
The typical characteristics of earthquake ground motion in the Osaka Plain are the later arrivals with large amplitudes that are considered to be generated at the edges of the basin structure. We found that the amplitudes of later arrivals have the azimuth dependency according to the location of the epicenters; the amplitudes of the later arrivals generated by the southern earthquakes are larger than those generated by the northern earthquakes. It is found that the azimuth dependency is not caused by the source effects but by the effects of the basement structure. The basin structure of the Osaka Plain in the N-S direction was obtained through refraction seismic surveys. The survey lines were extended in both north and south directions from the explosion point at a northern area of the Osaka Port; each line had a length of $20-30 \mathrm{~km}$.

The modified Aki and Larner (A-L) method was applied to study the azimuth dependency of the amplitudes of the later arrivals using the surveyed N-S section. From the calculation, the later arrival had a group velocity of $600 \mathrm{~m} / \mathrm{s}$ which corresponded well to the observed velocities. The azimuth dependency, however, was not well simulated. It is supposed that the incongruity was caused by insufficient information on the edge structure of the sedimentary basin and the structure of shallow sediments.
\end{abstract}

\section{Introduction}

The Osaka Basin is composed of very thick sedimentary layers. On a sediment-filled basin structure, surface ground motions are known to show larger amplitude and longer duration, and are more affected by surface waves than those on surrounding mountains.

Toriumi and his research group have maintained their seismic observation network in the Osaka Basin for more than 20 years studying basin effects on ground motions (The Calamity Science Institute, 1984, 1990) (Fig. 1). Some of these seismograms have been published. Much progressive research was made by using the seismograms (Toriumi, 1980; Toriumi and Segawa, 1988; Yokoyama and Toriumi, 1988). Matsunami et al. (1989) also have been constructing their broad frequency band observation network in the Osaka Plain since 1988. In this paper, we analyzed the seismograms from these networks.

Received November 20, 1990; Accepted October 25; 1991

* To whom correspondence should be addressed. 


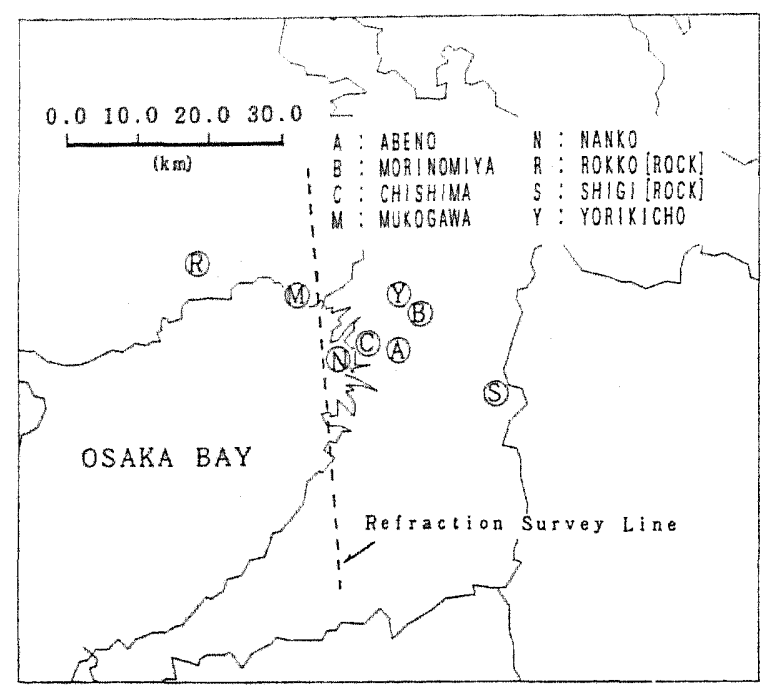

Fig. 1. Location of seismic observation sites in Osaka (The Calamity Science Institute, 1984, 1990) and seismic refraction survey line used in this study (Kagawa et al., 1990).

Seismograms of the Osaka Basin have been characterized by later arrivals, which appear 20-30 s behind the main shear wave group. Using the group velocity of the later arrivals of about $600 \mathrm{~m} / \mathrm{s}$, Toriumi (1980) showed that the later arrivals were the surface waves generated at the edges of sedimentary basin. We also found that the later arrivals had the azimuth dependency of amplitudes; the seismograms produced by the southern earthquakes have stronger later arrivals than those produced by the northern earthquakes.

The basin structure of the Osaka Plain in the N-S direction was obtained by refraction seismic surveys using large explosions (Kagawa et al., 1990). The survey lines were extended in both north and south directions from the explosion point at a northern area of the Osaka Port. The total length of the survey line was about $50 \mathrm{~km}$. The maximum thickness of the sedimentary layer was estimated to be larger than about $2,000 \mathrm{~m}$.

In this paper, the modified Aki and Larner (A-L) method (Aki and Larner, 1970; Bard and Bouchon, 1980, 1985; Geli et al., 1988; Horike, 1988) was applied to study the azimuth dependency of the later arrivals and their group velocities using the surveyed $\mathrm{N}-\mathrm{S}$ section. Ricker's wavelets are used as inputs for the simulations to demonstrate the two features of surface ground motions in the Osaka Plain (group velocity and azimuth dependency).

\section{General Characteristics of Earthquake Ground Motion in the Osaka Plain}

Toriumi(1980) found that the typical characteristics of earthquake ground motion in the Osaka Plain were the later arrivals with large amplitude. He considered that these 
later arrivals were surface waves generated at the edges of basin structure from the estimated group velocities of about $600 \mathrm{~m} / \mathrm{s}$. Figure 2 shows a comparison between the accelerograms of the sedimentary site (Abeno) and the rock sites (Shigi (a) and Rokko (b)) which were recorded at the same time. In the figure we can easily see that the records at the rock sites have quite simple wave forms without the later arrivals, whereas the wave forms at the sedimentary site are complicated. It can be seen that even in the deep source case (source depth of $70 \mathrm{~km}$ against epicentral distance of $50 \mathrm{~km}$ ), the later
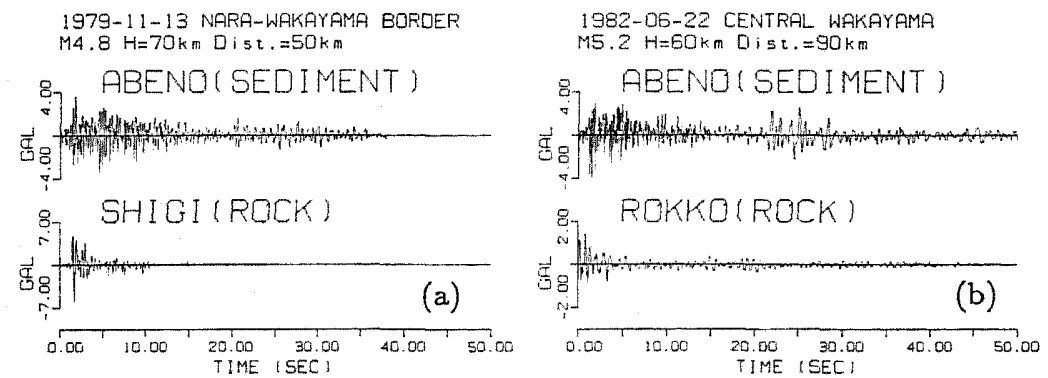

Fig. 2. Accelerograms at the sedimentary site (Abeno site; upper figures) and rock sites (Shigi site (a) or Rokko site (b); lower figures). These show the typical difference of the later arrivals observed at the two types of sites; the accelerograms of the sedimentary site have remarkable later arrivals while those of the rock sites do not have later arrivals.

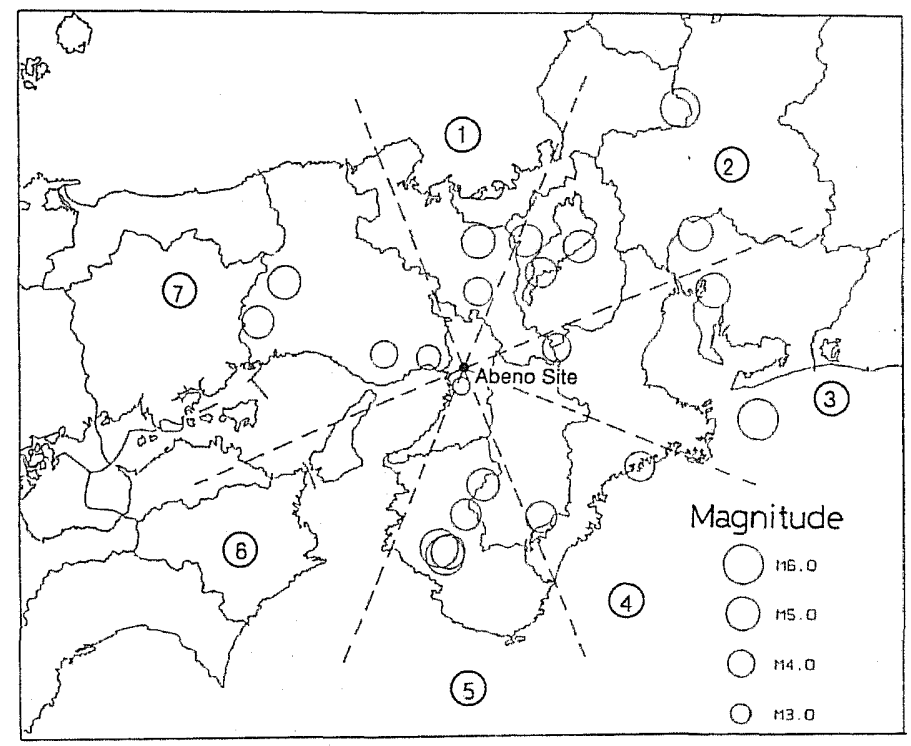

Fig. 3. Distribution of epicenters used in this study. The epicenters are divided into seven areas radiating from the Abeno observation site.

Vol. 40 , No. 1,1992 


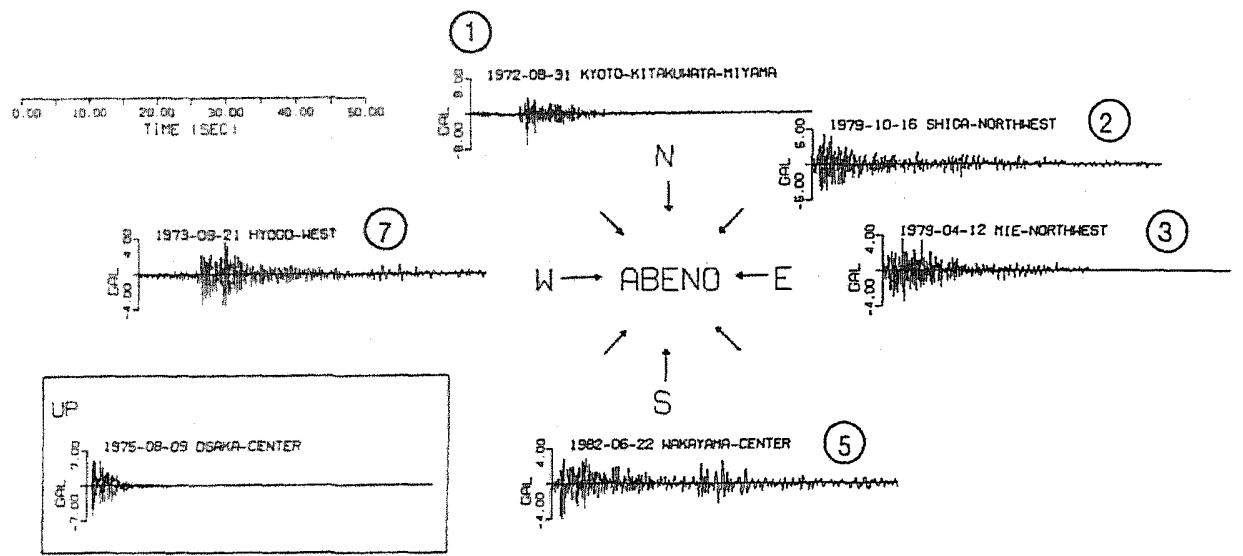

Fig. 4. Difference of wave shapes depending on the epicentral area divided as shown in Fig. 3. The numbers attached to waves correspond to the numbers of divided areas in Fig. 3. All waves are observed at the Abeno observation site. The epicenter of the wave in the box is just below the Osaka Plain. The seismogram from the earthquake whose epicenter is in the southern area has remarkable later arrivals, whereas others do not. This is a common characteristic that can be easily found in whole earthquakes shown in Fig. 3.

arrivals predominated at the sedimentary site but not at the rock sites (Fig. 2(a)). From this evidence, it seems that the generation of the later arrivals recorded at Abeno are caused by the effects of deep basin structure, not by source effects.

The following is a study which shows a strong azimuth dependency of amplitudes of later arrivals observed in the Osaka Plain. Several records at the Abeno site of Toriumi's network (The Calamity Science Institute, 1984, 1990) (Fig. 1) from earthquakes with different azimuths (Fig. 3) were selected and are shown in Fig. 4. Earthquakes selected from Toriumi's database are as shown in Figs. 3 and 4 . They have magnitudes of 4.3 to 6.1 , epicentral distances of 20 to $150 \mathrm{~km}$ and source depths of 10 to $70 \mathrm{~km}$, with the exception of the earthquake just below Osaka City. Figure 3 also includes the earthquakes that generate the accelerograms shown in Fig. 2. The numbers of divided areas in Fig. 3 correspond to the numbers of the waves in Fig. 4. All accelerograms in Fig. 4 are the N-S component because it is the only component commonly observed by Toriumi's network. In Fig. 4, we find the amplitude variations of the later arrivals. The strongest later arrivals are found in earthquakes whose epicenters are south of Osaka. On the contrary, the weakest later arrivals are found in earthquakes whose epicenters are located north of Osaka. Such azimuth dependency is easily detected in all the accelerograms we analyzed (see Fig. 3). Thus we conclude that the amplitudes of later arrivals have strong azimuth dependency and that the azimuth dependency is caused by the difference of structures between the northern and southern edges. To study the azimuth dependency further, the basin structure beneath the Osaka Plain is examined below. 


\section{Basin Structure of the Osaka Plain Obtained from Seismic Surveys}

A series of seismic refraction and reflection surveys has been conducted to examine the basin structure of the Osaka Plain. Hokko Island in the northern area of Osaka Port, being reclaimed at the time, was selected as the explosion site in 1988. We participated in the seismic refraction survey and observed the motions along two lines extending north and south from the explosion site. Figures 5 and 6(a) show two of the observation lines and arrival times along the lines, respectively.

Because no reverse explosions were made at the ends of the observation lines, it was difficult to apply a conventional analysis such as the "method of difference" to the observed travel times for head waves. However, some results of the reflection seismic survey at Hokko Island gave useful information for the refraction analysis. Based upon the analysis of the reflection survey, the surface layer was estimated to have a thickness of about $1.6 \mathrm{~km}$ with the RMS (Root Mean Squared) P-wave velocity of $2.15 \mathrm{~km} / \mathrm{s}$ at Hokko Island (Yokota, personal communications).

Adopting the P-wave velocity of the baserock in the Osaka Basin as $5.37 \mathrm{~km} / \mathrm{s}$ (Kagawa et al., 1990), the thickness of the surface layer along the survey lines was analyzed assuming a simple model of single surface layer on baserock. The obtained basin structure is shown in Fig. 6(b). The deepest point of the baserock was found

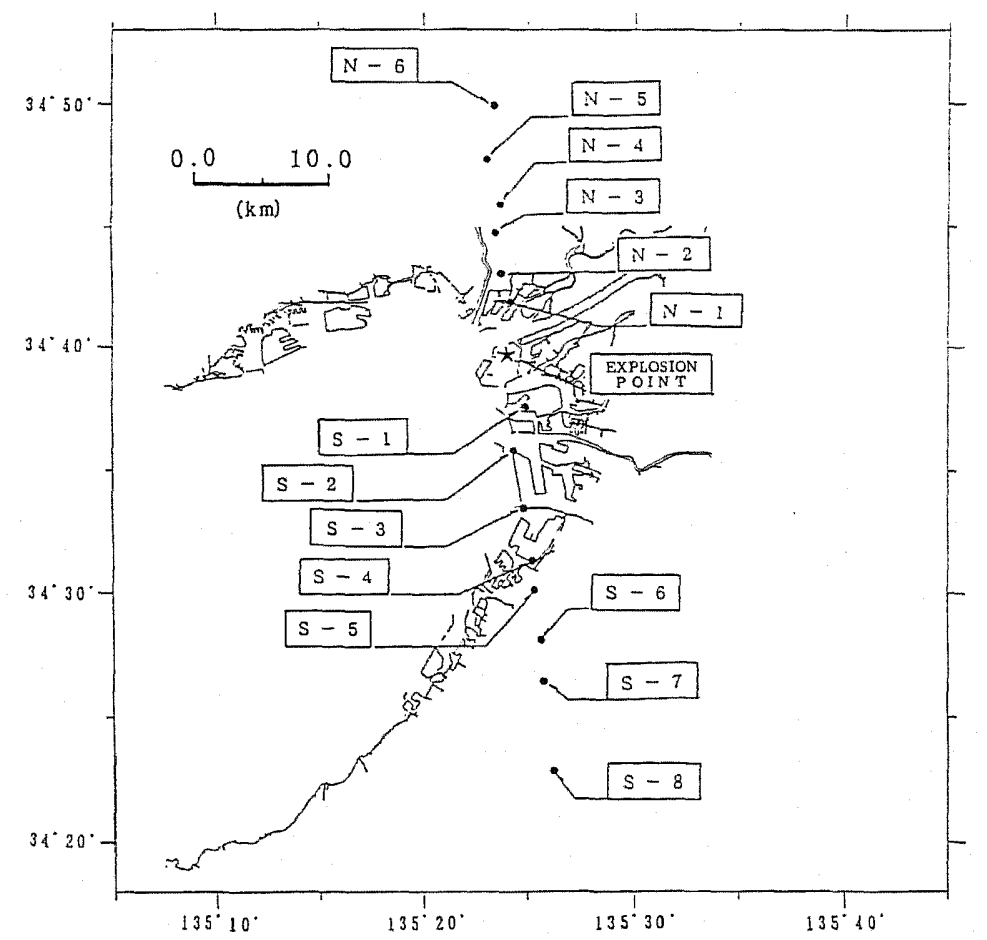

Fig. 5. Locations of source (solid star) and observation points (solid circles) of refraction survey in Osaka used in this study.

Vol. 40, No. 1, 1992 


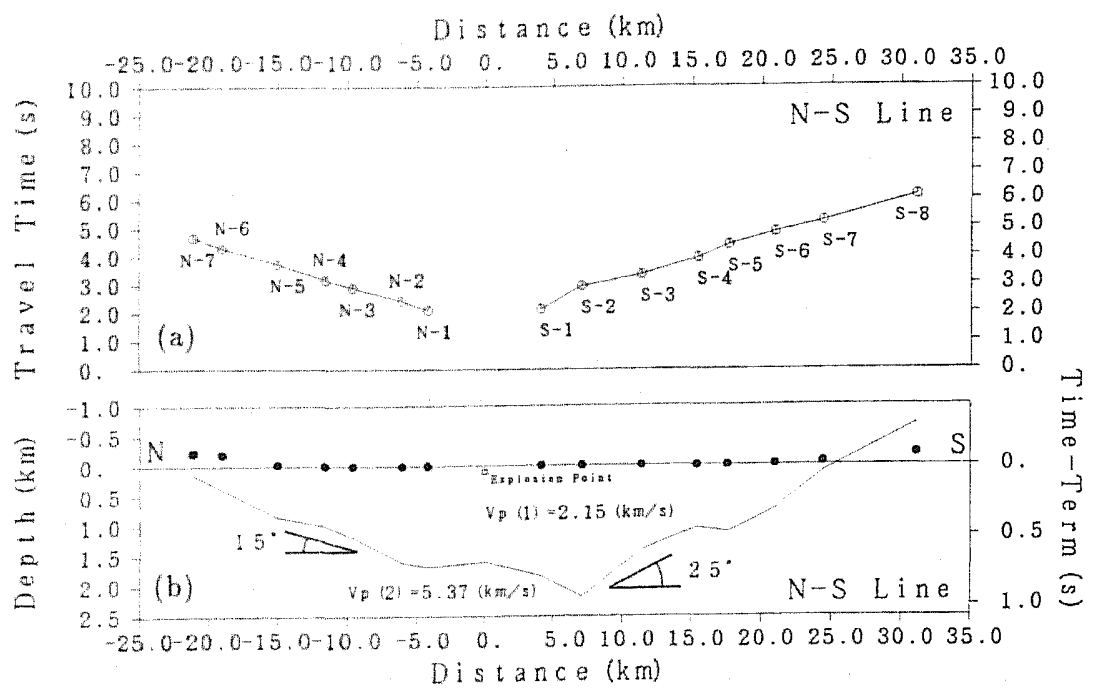

Fig. 6. (a) Head wave travel times at observation sites along N-S section and (b) N-S section of the Osaka sedimentary basin derived from refraction survey (Kagawa et al., 1990). The mean dip angles of southern and northern slopes are found to be 25 and 15 degrees, respectively.

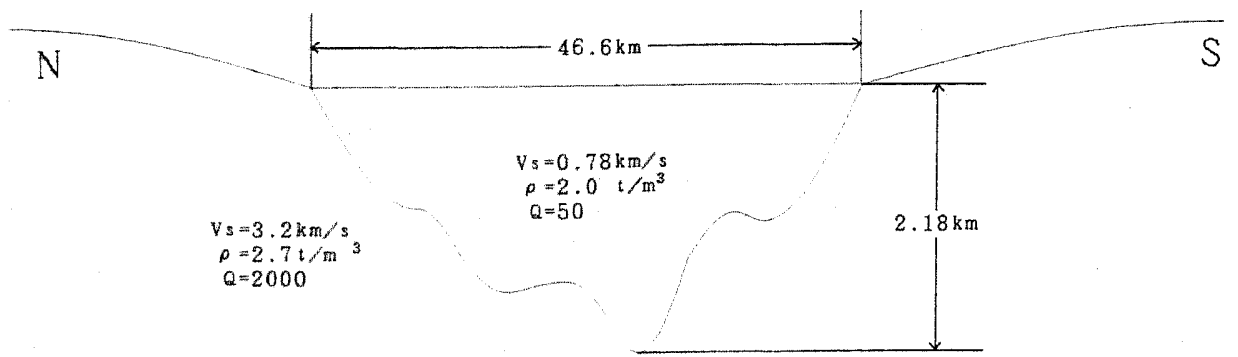

Fig. 7. Model structure used in simulations by Aki and Larner method. Structure shape is smoothed from Fig. 6 (b), and S-wave velocities are assumed from experimental study (Ohta et al., 1985).

several kilometers south of the explosion point and the corresponding maximum thickness reaches more than $2,000 \mathrm{~m}$. The thickness of the sedimentary surface layer decreases with the increase of the distance away from the deepest point, and the mean dip angles of southern and northern slopes are found to be 25 and 15 degrees, respectively. The detailed analyzing processes were shown in Kagawa et al. (1990). We anticipated that the difference of the mean dip angles of southern and northern slopes caused the azimuth dependency.

Based upon the basin structure investigated by the refraction survey, we applied the modified A-L method to find the characteristics of surface ground motions along 
the N-S section of the Osaka Basin due to upcoming SH-waves from the baserock. In the case of an N-S component computation with the N-S section, P-SV and Rayleigh waves' mode would be the standard approach. However, we applied the SH and Love waves' mode, because we simply wanted to know whether the small difference of the boundary structures of southern and northern areas (Fig. 6) caused the azimuth dependency or not.

The shear wave velocities in each layer were calculated by the following experimental relationship between $\mathrm{P}$ - and $\mathrm{S}$-wave velocities obtained from soils and rocks in Japan (Ohta et al., 1985);

$$
V_{\mathrm{P}}=0.0179 V_{\mathrm{S}}^{3}-0.215 V_{\mathrm{S}}^{2}+1.98 V_{\mathrm{S}}+0.707 .
$$

The velocities of S-waves are obtained as 0.79 and $3.2 \mathrm{~km} / \mathrm{s}$ for the surface and rock layers. Densities of these layers are also given as 2.0 and $2.7 \mathrm{~g} / \mathrm{cm}^{3}$ as the typical value of soils and granite rocks, respectively. The $Q$-values for each layer are assumed to be 50 and 2,000 as shown in Fig. 7.

\section{Simulations of Ground Motions in the Osaka Plain}

Applying the modified A-L method to the present study, the section obtained from the seismic refraction survey was further simplified to a simulation model so as to have a smoother change of boundary. Cosine functions with a quarter period are used to construct the smooth boundary. The boundary includes 1,024 digit points with $100 \mathrm{~m}$ intervals. The calculations were made up to as short a period as possible (the range from 204.8 to $0.98 \mathrm{~s}$ ). The wave-number is defined so as to be able to compute the surface waves as $\omega / V_{\mathrm{S}}$, where $\omega$ is an angular frequency and $V_{\mathrm{S}}$ is a shear wave velocity.

We adopted the Ricker's wavelet as the input wave function. Through the spectral study shown in Fig. 8 (Kameda, 1975), the observed later arrivals had the predominant period between 0.5 and $2.0 \mathrm{~s}$. Then the predominant period of the Ricker's wavelet was defined as $2.0 \mathrm{~s}$ to include the main power between 1.0 and $2.0 \mathrm{~s}$. The incident angle was defined as 0.5 radians (about 30 degrees); this was the smallest incident angle from the earthquakes shown in Fig. 2. The smallest angle was selected so as to generate the least surface waves.

Figure 9 shows the case of a southward input. The ground motions computed at the rock surface (points 1 and 11) are simple. On the contrary, the calculated response motions at the points within the Osaka Plain became much more complicated. The wave groups are separated into direct shear waves and later arrivals of surface waves as shown in Fig. 9 with different marking lines for each wave train. The surface waves are generated at the edges of the boundary between the rock and surface layers, and they travel along the surface with a group velocity of about $600 \mathrm{~m} / \mathrm{s}$. Toriumi (1980) also found the same velocity value for the surface wave group traveling along the Osaka Plain by analyzing the accelerograms recorded by his observational network. The positive correspondence between the group velocity of the present computation and the observed results confirms the obtained N-S section and S-wave velocities of the Osaka Basin assumed in this study. Through the simulation shown in Fig. 9, the group velocity of

Vol. 40, No. 1, 1992 


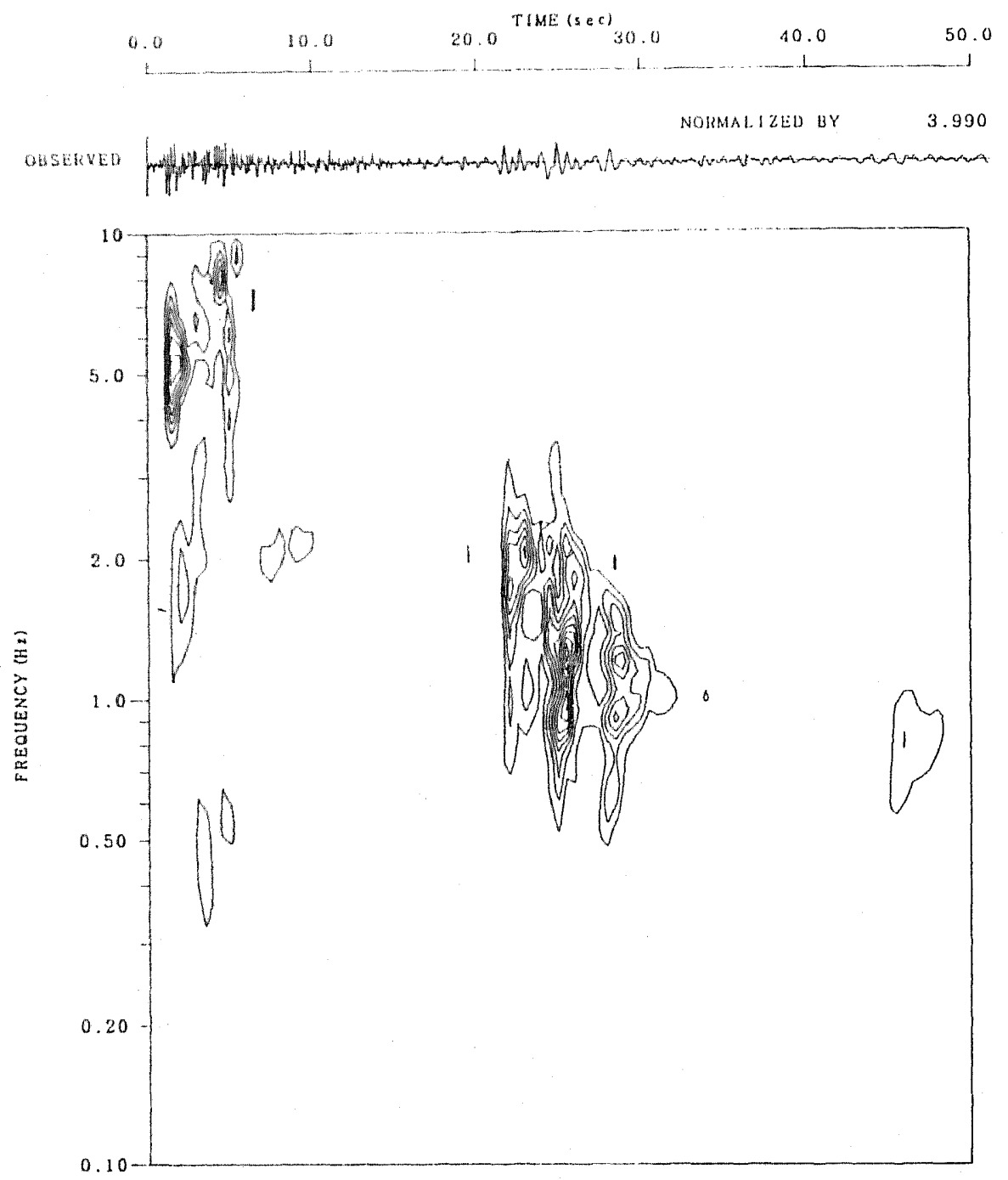

Fig. 8. Evolutionary power spectrum of the accelerogram at the Abeno site from the Central Wakayama earthquake of June 22, 1982; a case of southward input in Fig. 3. The predominant period of the later arrivals ranges from about $0.5 \mathrm{~s}$ $(2.0 \mathrm{~Hz})$ to about $2.0 \mathrm{~s}(0.5 \mathrm{~Hz})$.

later arrivals and general wave forms observed in the Osaka Plain were clearly demonstrated.

To confirm the azimuth dependency, the case of a northward input was calculated. The result is shown in Fig. 10. Here the later arrivals were also generated with an amplitude as large as that of the southward input shown in Fig. 9. Our simulation was unable to explain the observed azimuth dependency. 


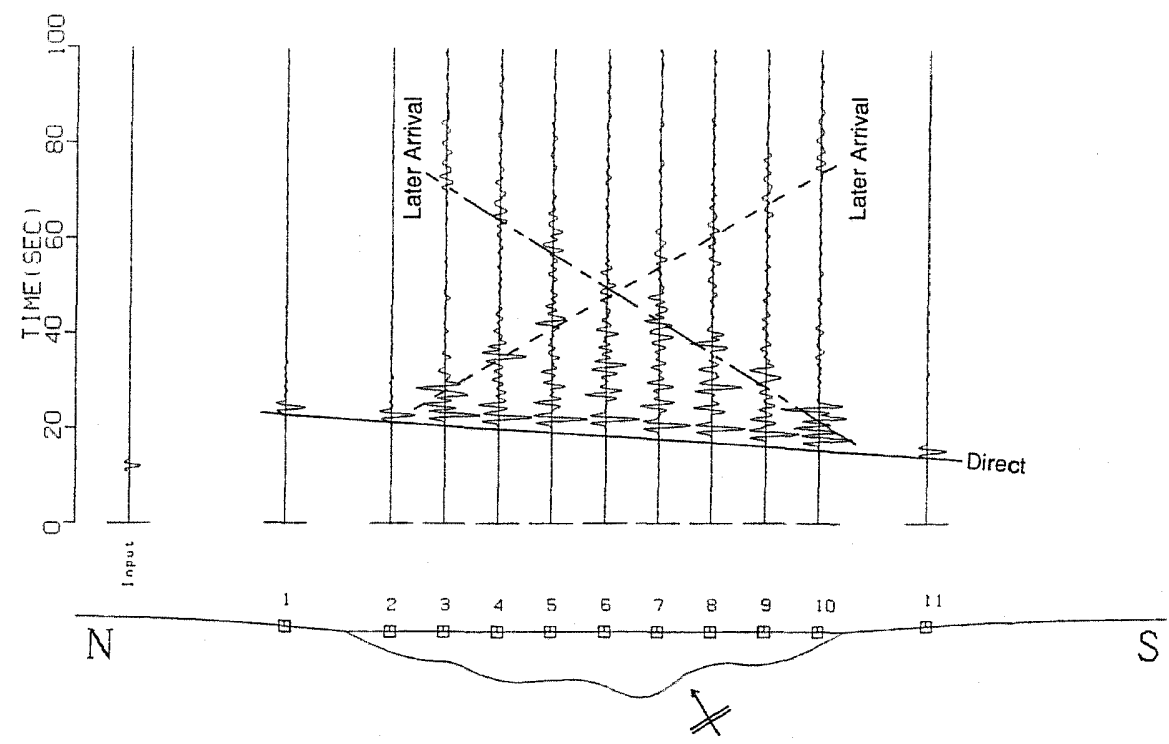

Fig. 9. Result by Aki and Larner method. Input wave is Ricker's wavelet with a predominant period of $2.0 \mathrm{~s}$ coming from southward with an incident angle of 30 degrees. The wave groups are separated by their characteristic patterns into direct shear waves and later arrivals of surface waves as shown by different marking lines.

\section{Discussion}

The group velocities of later arrivals in the Osaka Plain were clearly simulated by applying the modified A-L method to the surveyed N-S section obtained from the seismic refraction survey. However, the observed azimuth dependency of the later arrival amplitude was not well simulated.

We considered two reasons why azimuth dependency could not be effectively demonstrated by simulations. First, some difference in the dipping structure between the north and south edges was not well represented by the N-S section obtained from the seismic refraction survey. The resolution of the seismic refraction survey around the edges of the sedimentary basin was not high enough to explain the difference in dipping structure between the north and south basin edges. Second, the shallow layers also affected the azimuth dependency, since the predominant period of the later arrivals of about $1.0 \mathrm{~s}$ was comparatively short considering the deep baserock structure. To predict the long period strong motions in the Osaka Plain for practical engineering applications, the detailed basin structure (including information on shallow layers beneath Osaka) must be studied further.

\section{Conclusions}

Based upon the analysis of seismograms on the Osaka Plain and the numerical Vol. 40, No. 1, 1992 


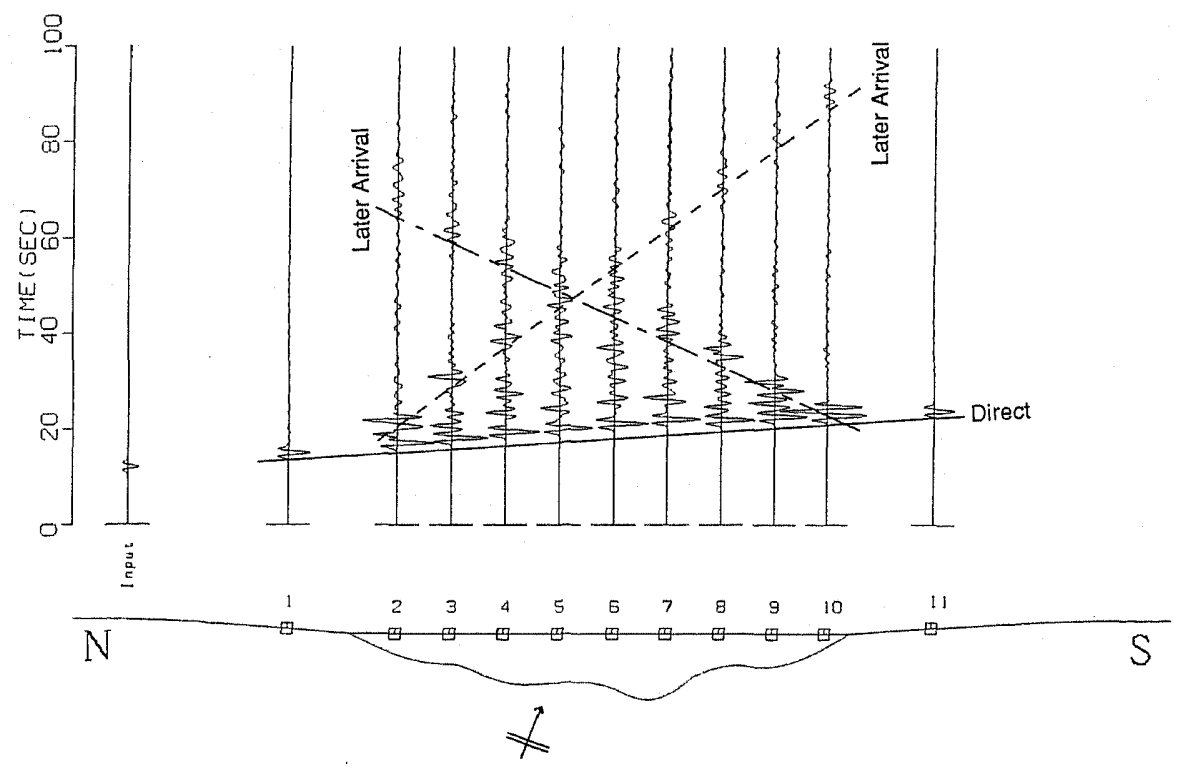

Fig. 10. Result by Aki and Larner method. Input wave is Ricker's wavelet with a predominant period of $2.0 \mathrm{~s}$ coming from northward with an incident angle of 30 degrees. The wave groups are separated by their characteristic patterns into direct shear waves and later arrivals of surface waves as shown by different marking lines.

simulation of the earthquake ground motion on the Osaka Plain, the following conclusions were arrived at:

1) The later arrivals observed in the Osaka Plain show strong azimuth dependency of amplitude; the seismograms of southern earthquakes have stronger later arrivals than those of northern earthquakes.

2) The group velocity of the later arrivals computed by the modified A-L method for the surveyed N-S section corresponded well with the observed group velocity of about $600 \mathrm{~m} / \mathrm{s}$.

3) Simulations using the modified A-L method could not clearly demonstrate the azimuth dependency of the amplitudes of the later arrivals.

4) In order to solve the problems on the azimuth dependency, further surveys of structure are required.

We wish to thank Prof. Toriumi who prepared the observed data on the Osaka Plain in his study. These data motivated us to perform and helped us in this study. Prof. Irikura, Dr. Horike, Dr. Matsunami, and Dr. Iwata gave important suggestions to us throughout this study. We used slightly modified version of Dr. Horike's computation program of the Aki and Larner method. Mr. H. Yokota kindly shared with us his analysis outcome of reflection records near the explosion point in Osaka. We wish to thank reviewers who helped us to complete this paper. To create the explosion and resulting observations, we were helped by many individuals, especially Miss $\mathrm{N}$. 
Matsuyama whose assistance was especially appreciated. We also want to thank the City of Osaka for its help in carrying out the refraction survey.

\section{REFERENCES}

Aki, K. and K. Larner, Surface motion of a layered medium having an irregular interface due to incident plane SH waves, J. Geophys. Res., 75, 933-954, 1970.

Bard, P. Y. and M. Bouchon, The seismic response of sediment-filled valleys. Part I. The case of incident SH waves, Bull. Seismol. Soc. Am., 70, 1263-1286, 1980.

Bard, P. Y. and M. Bouchon, The two-dimensional response of sediment-filled valleys, Bull. Seismol. Soc. Am., 75, 519-541, 1985.

Geli, L., P. Y. Bard, and B. Jullien, The effect of topography on earthquake ground motion. A review and new results, Bull. Seismol. Soc. Am., 78, 42-63, 1988.

Horike, M., Analysis and simulation of seismic ground motions observed by an array in a sedimentary basin, J. Phys. Earth, 36, 135-154, 1988.

Kagawa, T., S. Sawada, Y. Iwasaki, and S. Emi, Structure of Osaka sedimentary basin derived from explosion, Zisin (J. Seismol. Soc. Jpn.), Ser. 2, 43, 527-537, 1990 (in Japanese with English abstract).

Kameda, H., On a method of computing evolutionary power spectra of strong motion seismograms, Proceedings of Japanese Civil Engineering Society, Vol. 235, 55-62, 1975 (in Japanese).

Matsunami, K., K. Irikura, T. Iwata, H. Fujiwara, and I. Matsui, Seismic observations in and around Osaka Plain using seismograph systems with wide dynamic characteristics over broad frequency band (0.0017 to $30 \mathrm{~Hz}$ ), Annu. Disas. Prev. Res. Inst., Kyoto Univ., 32B-1, 53-60, 1989 (in Japanese with English synopsis).

Ohta, T., M. Niwa, K. Takahashi, and N. Yahata, The relationship of $V_{\mathrm{p}}, V_{\mathrm{S}}$ and Poisson ratio evaluated by physical surveys and laboratory tests, Programme and Abstract of Seismological Society of Japan, Spring, B12, 1985 (in Japanese).

The Calamity Science Institute, Characteristics of Ground Motion on Osaka Plain, Osaka, 309 pp., 1984 (in Japanese).

The Calamity Science Institute, Characteristics of Ground Motion on Osaka Plain. Phase II. Characteristics of Long Period Ground Motion, Osaka, 303 pp., 1990 (in Japanese).

Toriumi, I., Characteristics of ground motion on Osaka Plain, Proceedings of Japanese Architecture Society (Kinki distinct), 487-488, 1980 (in Japanese).

Toriumi, I. and T. Segawa, Mechanism of Rayleigh type surface wave in sedimentary plain, Proceedings of 9th WCEE, II, 557--562, 1988.

Yokoyama, H. and I. Toriumi, Behaviors of alluvial plain with irregular topography by the wave propagation. Part 2, Proceedings of 9th WCEE, II, 707-712, 1988.

Vol. 40, No. 1, 1992 